\title{
COMPOSIÇÃO PROXIMAL E CARACTERIZAÇÃO DE ATIVIDADE ANTIOXIDANTE DA SEMENTE DE JABUTICABA
}

\author{
Bruna Melo Miranda1-2; Lismaíra Gonçalves Caixeta Garcia1; Joelma Avemir Damacena \\ Pimenta1; Eduardo Ramirez Asquieri2; Clarissa Damiani1-2; Flávio Alves da Silva1-2; Caio \\ Cesar Cardoso1; Taynara Álvares Martins1 (bruuna.melo@ hotmail.com)
}

\author{
1 - Escola de Agronomia, Universidade Federal de Goiás (UFG), Brasil \\ 2 - Programa de Mestrado em Ciência e Tecnologia de Alimentos, Universidade Federal de Goiás (UFG), Brasil
}

A jabuticaba fruta tipicamente brasileira possui casca avermelhada, quase preta, polpa esbranquiçada e sabor adocicado. No processamento de produtos de jabuticaba, a casca e a semente são geralmente desprezadas, podendo representar até $50 \%$ do fruto in natura. Estes coprodutos podem ser utilizados nas indústrias de alimentos, devido seu alto valor nutricional. Objetivou-se por meio deste trabalho estudar a composição das sementes de jabuticaba por meio da caracterização química. Para a realização dos testes, os frutos foram espolpados e as sementes foram submetidas à caracterização química: antioxidante in vitro, compostos fenólicos, perfil de minerais, taninos condensados e hidrolisados e compostos cianogênicos determinados por teste de Guignard. Na composição proximal o que apresentou maior proporção em base seca foi teor de carboidratos $\left(94,46 \mathrm{~g} \cdot 100 \mathrm{~g}^{-1}\right)$ seguido pelos teores de proteínas $\left(3,60 \mathrm{~g} \cdot 100 \mathrm{~g}^{-1}\right)$, lipídeos $\left(1,02 \mathrm{~g} \cdot 100 \mathrm{~g}^{-1}\right)$ e cinzas $\left(0,92 \mathrm{~g} \cdot 100 \mathrm{~g}^{-1}\right)$. Os compostos fenólicos apresentaram maior extração no extrato aquoso $\left(66,44 \mathrm{mg} \cdot 100 \mathrm{~g}^{-1}\right)$, seguido pelo extrato etanólico $\left(51,28 \mathrm{mg} \cdot 100 \mathrm{~g}^{-1}\right)$ e extrato etéreo $\left(46,48 \mathrm{mg}, 100 \mathrm{~g}^{-1}\right)$. A atividade antioxidante in vitro foi obtida por diferentes métodos, onde os resultados por DPPH foram: extrato etéreo $\left(694,88 \mu \mathrm{g} \cdot \mathrm{mL}^{-1}\right)$, extrato etanólico $\left(396,05 \mu \mathrm{g} \cdot \mathrm{mL}^{-1}\right)$ e extrato aquoso $\left(322,44 \mu \mathrm{g} \cdot \mathrm{mL}^{-1}\right)$, já pelo método de ABTS os resultados foram: extrato aquoso $\left(32,26 \mu \mathrm{mol}\right.$ de Trolox. $\left.\mathrm{g}^{-1}\right)$, extrato etanólico $(13,46 \mu \mathrm{mol}$ de Trolox. $\left.\mathrm{g}^{-1}\right)$ e extrato etéreo $\left(10,71 \mu \mathrm{mol}\right.$ de Trolox. $\left.\mathrm{g}^{-1}\right)$, no método de FRAP foi possível detectar as quantidades no extrato etanólico $\left(23,46 \mu \mathrm{mol} \mathrm{FeSO}_{4} \cdot \mathrm{g}^{-1}\right)$ e aquoso $\left(104 \mu \mathrm{mol} \mathrm{FeSO}_{4} \cdot \mathrm{g}^{-1}\right)$. Dentre os macrominerais analisados, o potássio apresentou maior resultado $\left(7,20 \mathrm{mg} \cdot \mathrm{g}^{-1}\right)$, em seguida o fósforo $\left(1,50 \mathrm{mg} \cdot \mathrm{g}^{-1}\right)$, enxofre $\left(1,40 \mathrm{mg} \cdot \mathrm{g}^{-1}\right)$, magnésio $\left(1,00 \mathrm{mg} \cdot \mathrm{g}^{-1}\right)$, cálcio $\left(0,80 \mathrm{mg} \cdot \mathrm{g}^{-1}\right)$ e sódio $\left(0,12 \mathrm{mg} \cdot \mathrm{g}^{-}\right.$

$\left.{ }^{1}\right)$. Dentro do universo de microminerais, a maior concentração encontrada nas sementes de jabuticaba foi de ferro $\left(0,07 \mathrm{mg} \cdot \mathrm{g}^{-1}\right)$, seguido pelo boro $\left(0,03 \mathrm{mg} \cdot \mathrm{g}^{-1}\right)$, zinco $\left(0,02 \mathrm{mg} \cdot \mathrm{g}^{-1}\right)$, manganês $(0,02$ $\left.\mathrm{mg} \cdot \mathrm{g}^{-1}\right)$ e cobre $\left(0,01 \mathrm{mg} \cdot \mathrm{g}^{-1}\right)$. Os teores de taninos hidrolisáveis $\left(132,73 \mathrm{mg} \cdot 100 \mathrm{~g}^{-1}\right)$ foram superiores aos dos condensados $\left(43,73 \mathrm{mg} \cdot 100 \mathrm{~g}^{-1}\right)$. Foi observado que a semente de jabuticaba não apresenta glicosídeos cianogênicos. Dessa forma, a semente pode ser utilizada em produtos alimentícios, devidos aos seus teores significativos de compostos fenólicos, taninos e atividade antioxidante.

Palavras-chave: atividade antioxidante, jabuticaba, coprodutos. 